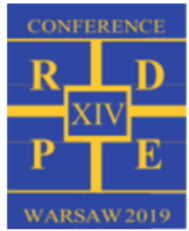

\title{
Virtual power plants - types and development opportunities
}

\author{
Arkadiusz Przychodzien ${ }^{1}$ \\ ${ }^{1}$ Institute of Heat Engineering, W arsaw U niversity of Technology, Power Generation Strategic A nalysis Department, PKN ORLEN, \\ arkadiusz.przychodzien@orlen.pl, Poland
}

\begin{abstract}
Modern power engineering meets new challenges. With the development of new energy production and storage technologies, creates new demands for energy services. To support this development, it is necessary to implement new teleinformatic systems that will allow for resource management. Such systems are called V irtual Power Plants (V PP). There are many definitions of this type of solutions due to the very wide range of possible applications. VPPs can be developed by many types of entities, e.g. distribution system operators, electricity generators, energy clusters. The ability to build a system based on modules allows you to customize the system to user's needs. An opportunity for the development of VPP will be a package "Clean energy for all Europeans" (so called "Winter package") that introduces regulations that allow for the development of renewable energy sources, including prosumers, and enables an active participation in the energy market for energy consumers. In addition, more stringent requirements for balancing production and energy consumption are introduced, requiring greater balancing accuracy.
\end{abstract}

\section{Introduction}

We are witnessing a great breakthrough in the energy sector in which we can observe changes in the shape of power systems and market models. Nowadays, power systems are dominated by large generation units owned by big power companies, while trends are moving towards a distributed generation model, consisting of a large number of smaller generation units owned by households and small enterprises. The development of small generation installations allowed many consumers to produce energy for their own needs, making them prosumers. The potential escape of prosumers from current energy suppliers has made them adapt their business models to retain customers by offering them new services and giving them the opportunity to cooperate.

Virtual Power Plants are one of the innovative solutions that fit the trend of distributed energy development. They are created to maximize the economic effect of units, but also to effectively balance the network. In VPPs an aggregator combines distributed units and manages them so that they are one unit selling energy on the market and offering system services. For this purpose aggregator optimizes VPP in real time, through the load forecasting, net-metering and automatic generation control. A bility to generate additional benefit occurs through the proper balancing of the production and consumption of energy in the system, while predicting the behavior of the market and the factors affecting the efficiency of power units. Obtaining such a result requires a high level of flexibility of production balancing and energy consumption using IT systems.
Further devel opment of uncontrollable renewable energy sources will cause that generation flexibility and demand control capability will gain significant value. This is one of the reasons why energy concerns are interested in the concept of virtual power plants. The idea of VPP gives the possibility of combining many technologies, such as conventional power plants, demand side response (DSR), prosumer installations, as well as energy storage. This combination allows generation of additional profits thanks to the synergy effect of cooperating technologies. VPP are an example of the "Internet of Things" using existing networks and IT systems to create services in the field of electricity generation, while avoiding large capital expenditures that would require the construction of new flexible peak sources. The use of a combination of existing resources gives many new opportunities, such as balancing deviations between the forecasted and actual generation of wind sources under V PP. This limits the business risk, reduces balancing costs and increases the network @ operational safety. [1]

The development of virtual power plants has many challenges on its way. One of them is a large diversity of market models and legal regulations in different countries. This makes impossible to copy ready-made VPP solutions developed in other countries. VPP must be tailor-made for a given system and energy market. This situation may change due to the entry into force of the package "Clean energy for all Europeans" al so called the "Winter Package". It contains a number of regulations enabling the development of renewable sources of energy, prosumer installations, increasing the rights of energy consumers, more flexible sales, combine and unify the European energy markets in order to create 
a common market for EU countries. Regulatory changes may create an appropriate environment for the development of VPP, allowing their operators to use the generating units even more efficiently and offer new services on the electricity market, e.g. on interconnectors.

The development of the VPP will also affect changes in the markets for electricity and energy resources, changes in the demand profile for electricity (e.g.. as a result of the development of electromobility ) forcing an increase in production efficiency. An important impulse for development may also be further progress in the field of electricity storage technologies, increasing the possibilities of optimal management of generating assets. The development of appropriate models of functioning suited to the regulatory and market environment as well as the needs of the system operators will be key for the development of VPPS, because other objectives will have an enterprise with large production units, and another group of cooperating prosumers.

\section{Virtual Power Plant definition}

There is no one clear definition of the Virtual Power Plant and the use of the term depends on the authors of the described solution. This definition is applied to a very wide range of terms, because it can only define the organizational structure connecting entities [2], in most definitions it refers to the IT system connecting entities, while in other definitions it is defined as a set of units together with the system. Generally, the Virtual Power Plant can be described as a system of generating, consuming and storing electricity units connected by means of an ICT system that accomplishes the assumed goals using IT systems.

\section{The purposes of creating Virtual Power Plants}

The shape and functionality of VPP depends on the purpose for which it was created. This purpose depends on the range of activities that the VPP's owner performs and is different due to the different role of the entity in the operation of the power system.

The objectives of the VPP's operation created by the energy producer:

- Increasing revenues from sales of energy generated by units through optimization of load. The use of flexibility of production in order to offer on the SPOT market and balancing electricity that meet the demand of customers.

- Reducing the risk of operations, e.g. imbalance of generation units on the energy market with the use of advanced forecasting modules and cooperation of many units. The possibility of quick and optimal reaction on unplanned events.

- Decreasing operating costs by unifying and integrating systems responsible for forecasting, optimization, control and reporting. No need to maintain separate systems and infrastructure, as well as less work to support the system.

- Ability to offer new system services for the needs of distribution network operators possible to implement thanks to the management of distributed sources.

The objectives of the VPP operation created by the distribution system operator:

- Increasing the security of the system by reducing the risk of rapid changes in units production or customers demand. VPP also provides the ability to predict network threatening situations, and in case of emergency situations, flexible network balancing while maintaining appropriate priorities.

- Reduction of operating costs of the distribution network through the optimal use of available resources, as well as the unification and integration of operator systems with source control systems that allows to limit the number of systems maintained.

- The use of power units for the system services

\section{Virtual Power Plant division}

We can divide them both due to the location of sources, the type of system control and its organization.

We can divide VPPs in terms of dispersion of units:

- Focused - units are located within one connection to the external power grid, e.g. a wind farm in which individual turbines play the role of elements managed by VPP.

- Distributed - units have a lot of connections to the grid, e.g. VPP managing a group of wind turbines connected in many places in the network

Distributed VPPs can also be divided in terms of the location of units:

- Regional - are located in a limited area and are connected to the same distribution network, e.g. local energy clusters, where the synergy effect is also achieved thanks to the possibility of optimizing the loads in the distribution network and reducing the related costs.

- Supra-regional - can be located in the whole power system using the model of "copper plate", the synergy effect is achieved by the operation of units on one energy market or through the delivery of distributed system services

According to [3] VPP, we can divide the type of control :

- Centralized Controlled Virtual Power Plant management takes place only in one central control unit responsible for all aspects of the VPP operation, which is 
connected directly to each DER (Distributed Energy Resource) managed by it

- Distributed Controlled Virtual Power Plant management takes place in a multi-level manner through the cooperation of control units of various levels, i.e. the central control unit issues commands to lower-order control units and they issue commands to the control units of the next order or to DERs

- Fully Distributed Controlled Virtual Power Plant DERs independently implement the control on the basis of data transferred by the VPP system, which has no direct impact on the functioning of generating units.

VPP can include many types of power units [4]:

- Uncontrollable Energy Sources - mainly Renewable Energy Sources, can occur both in the form of large generation units and smaller units requiring coordination.

- Controllable Energy Sources - they can exist occur as large generation units (coal fired units or CCGT), as well as smaller units, e.g. small cogeneration for the needs of a district heating system, and also controllable renewable energy sources, such as biogas, can be included in this group.

- Energy storage - they can occur both as large energy stores built to balance the network by the operator or large RES producers, as well as small energy stores installed in homes or smaller companies to balance and ensure the security of energy supply by its customers.

- Energy consumer - they can appear both as large industrial recipients, small and medium enterprises, local government units, public institutions and households.

In addition, consumers can be divided into the following categories:

- Passive - they are only consumers of electricity, they do not carry out any VPP management center commands, they only provide data on demand plans and measurement data.

- Active - having the tools and opportunities to change the volume of charged electricity:

- Prosumers - having their own generation sources and producing a part of energy for their own needs, as well as having the opportunity to resell energy to the power grid (at this point they are included in the VPP balance sheet as an energy source).

- DSR (Demand Side Response) - have ability to temporary decrease charged electricity by using own generation, energy stores or limiting of consumption.

\section{Modules of the management centre}

The universality of VPP applications means that the construction of the management center should meet the various needs of the aggregator and be able to change or expand depending on the needs. Therefore, the best solution in the construction of this type of systems is the use of a modular structure. The modules communicate with each other send information in a unified form. Additionally, thanks to the separation of individual modules, it is possible to update one of them, not the entire system. Similarly in the case of failures or errors, the protection at the module boundaries prevents them from spreading throughout the system.

The division into modules can have a different shape due to the needs of the users. An example of a division to cover basic VPP functionalities:

- Balancing module - responsible for scheduling production and consumption of electricity, participation in the Balancing Market, ongoing monitoring of production and energy consumption, balancing units within VPP.

- Forecasting module - forecasting the electricity demand and production of renewable sources, as well as the market situation on the basis of analyzes and external data, e.g. meteorological data.

- Production optimization module - calculation of optimal load distributed for each unit using economic and technical criteria.

- Trade module - trading electricity on the market, offering on the stock exchange, settlements of contracts.

- Analytical module - a wide range of analyzes of both internal factors such as technical capabilities of devices as well as external factors related to the market and power system.

- System services module - offering distribution and transmission system operators services services related to power reserves or regulation of system operation, performance of obligations resulting from capacity market contracts.

- Reporting module - fulfilment of reporting obligations in the scope of electricity generation and trading resulting from REMIT and other regulations.

\section{An example of the operation of VPP}

\subsection{Integration of large and distributed power units}




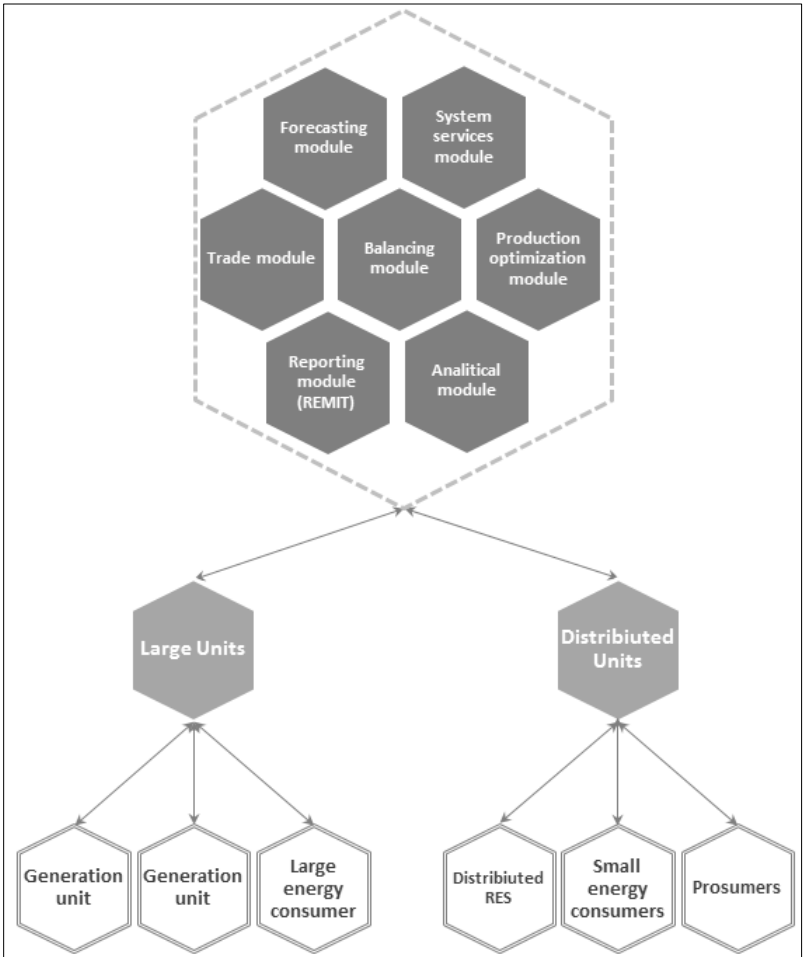

Fig. 1. Integration of large and distributed power units.

The first example of the use of VPP is the integration of units with a diverse work character and the volume of produced and consumed electricity.

Such VPPs may include:

- Large generation units and large electricity consumers:

- Generation units - conventional flexible power stations, electricity is produced continuously to cover the demand of industrial customers or the market demand

- Large consumption units - industrial plants consuming large amounts of electricity, characterized by continuity of demand and requiring power reliability due to production processes

- Distributed units:

- Many small electricity consumers - a network dispersed over a large area, characterized by high volatility of electricity demand and small volume of individual consumers

- Distributed renewable energy sources - a network of small and micro installations generating electricity, e.g. photovoltaic or wind turbines dispersed over a large area, are characterized by high variability and the inability to control the level of electricity production.

- Prosumers - units being both the consumer and the generator of electricity, part or all of the energy generated by the source is consumed on-side and in the case of excess or deficit of energy is balanced by the external network.

\subsection{Integration of energy units operating in a limited area (clusters)}

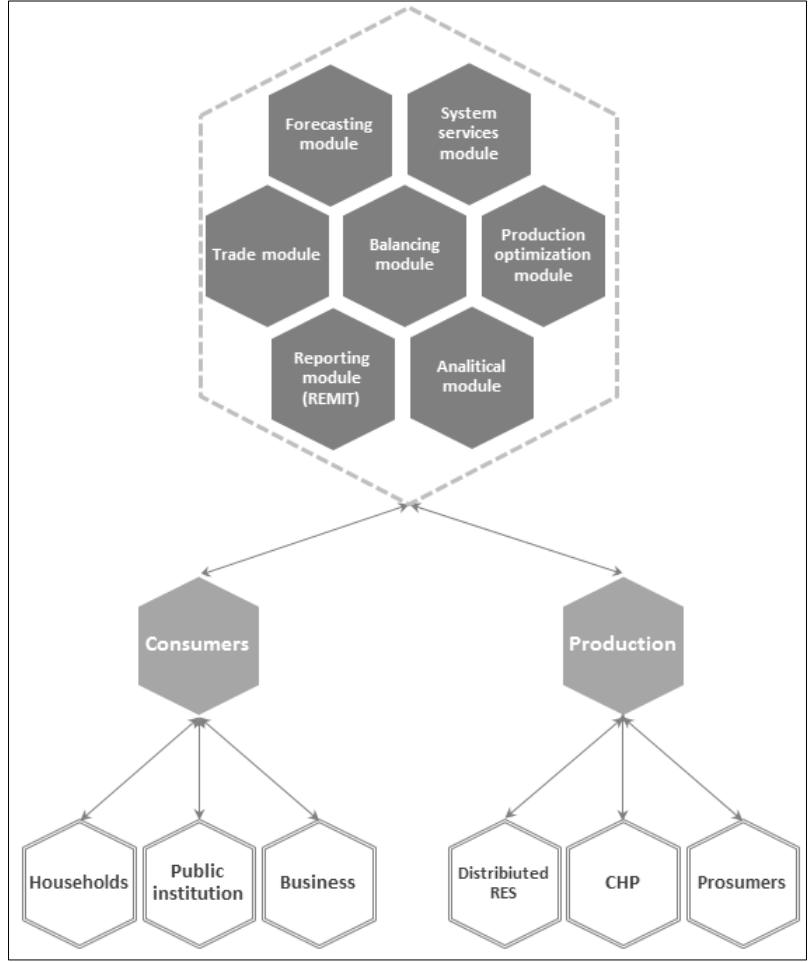

Fig. 2. Integration of energy units operating in a limited area

The second example of the use of VPP is the integration of units operating within the so-called "energy clusters", being a form of energy cooperative operating in a limited area that gathers local generation units and consumers for the purpose of regional development of renewable energy sources, as well as reducing energy and distribution costs.

Such VPPs may include:

- Electric energy consumers:

- Households - recipient with an obligatory approved tariff for electricity, characterized by high volatility and low volume of energy consumed by individual consumer, depending on the type of the cluster could be the main group of consumers,

- Public institutions - this group includes offices, schools, local government institutions, characterized by high volatility and moderate volume of energy consumed by individual consumer

- Companies - depending on the type of their business activity can be characterized by both stable and large volume or variable and low level of the volume of consumed energy

\section{- Production units:}

- Distributed renewable energy sources - a network of small and micro installations generating electricity, e.g. photovoltaic or wind turbines distributed over a large area, are characterized by high variability and the inability to control the level of electricity production.

- Local heat and power plants - generating units producing electricity and heat for the needs of the local 
heating network, depending on the technological system there is a possibility to change the level of energy production,

- Prosumers - units being both the consumer and the generator of electricity, part or all of the energy generated by the source is consumed on-side and in the case of excess or deficit of energy is balanced by the external network.

\section{Regulatory and market environment affecting the development of Virtual Power Plants}

\subsection{Winter Package}

On November 30, 2016, a package of legislative proposals was published. "Clean energy for all Europeans" (so-called " Winter Package ") containing a set of directives and regulations that together create a new model of the European electricity market. These documents define the rules support energy renewable, functioning common electricity market in the EU, define the principles of energy security and risk management, promoting the development of energy efficiency and functioning of regulatory authorities.

The entire Winter Package consists of 8 documents, but for the functioning of VPPs, the most important are 3 of them concerning common rules of the electricity market and renewable energy sources:

- Directive on the promotion of the use of energy from renewable sources

\section{- Regulation on the internal electricity market}

- Directive on common rules for the internal market in electricity

Their importance for the development of VPP results from the establishment of clear rules enabling the functioning of such systems in all EU countries, as well as through support for renewable energy sources (including largely prosumer sources ) will increase the demand for such systems balancing and managing production sources.

\subsection{Regulation and Directive on common rules for the internal market in electricity}

The most important documents of the "Winter Package" are the Regulation and the Directive on common rules for the internal market in electricity. They contain articles that will have the strongest impact on the shape of the new common electricity market in the European Union. These documents concern the functioning of wholesale energy markets, network balancing, the operation of generation capacity mechanisms, as well as end-user service in concluding contracts with it, energy bills and the possibility of their active participation in the market.

Significant changes will be introduced in the functioning of SPOT and balancing markets. Due to the fact that these markets make it possible to participate in a larger number of flexible resources. It is necessary to implement an effective pricing mechanism so that it reflects power shortages and encourages market participants to actively respond to market signals. Thanks to the possibility of recovering the costs incurred in the moments of unbalancing the network, flexible resources will be available when the market needs them most without the need to implement additional power mechanisms. Therefore, all market participants should be financially responsible for imbalance that they cause in the system, while imbalance prices should reflect the value of energy in real time. It is also necessary to change electricity price limits on wholesale markets, so that they are flexible and automatically adjust to the market situation reflecting the maximum value of nondelivered energy. Additionally, until January 1, 2021, the imbalance settlement period must be 15 minutes in all graphic areas, unless regulatory authorities granted a derogation from this rule (by 31 December 2024 at the latest). All these changes introduce greater risk to the activity of energy market participants, and require them to have higher than previously quality forecasting of production and consumption levels. They also give a chance to obtain better economic results of units by using the available flexibility of units. All these circumstances create a space for the development of VPPs that will optimally manage and balance all energy resources, both reducing the risk of imbalance and giving the opportunity for additional revenues.

An important part of the energy market will be consumers. Until now, they were passive and most often bought electricity at regulated prices. This makes the offer for them unrelated to the market. On the one hand, it protects them from the risk of a sudden increase of prices, but on the other hand it does not give full opportunity to optimize their consumption, as would be in the case with dynamic prices. The introduced changes give each consumer the right to active participation in the energy market, directly or through the aggregator. In addition, the obligation to change the seller within 24 hours will be introduced, as well as the possibility of having several energy purchase contracts from many suppliers. These changes will positively affect the competitiveness of energy sales offers, and by simplifying and making the processes more flexible, they will activate the consumers to change the seller. The greater demand for such services will mean that entities offering such contracts will need tools such as VPPs that will allow flexible management of the constantly changing portfolio of consumers.

Another important element of the new common electricity market will be its full digitization. During the introduction of smart metering systems, many models of 
managing these data were created. It is necessary to introduce transparent rules of access to data on nondiscriminatory terms and providing cyber security. These systems will enable active participation of consumers in the electricity markets if they are interoperable and able to generate the data needed for the proper functioning of consumer energy management systems. For this purpose, appropriate standards implementing the best practices in this area should be applied, so that market participants can easily adapt their IT systems to uniform technical requirements. The introduction of uniform principles of smart metering will facilitate the development of VPP through the possibility of applying the same standards in the areas of various operators and various energy markets. This will improve the offer of IT solutions in this area, because it will be possible to easily transfer the best solutions used in this field in other systems and will eliminate the need to develop many standards adapted to different energy markets. [5] [6]

\subsection{Directive on the promotion of the use of energy from renewable sources}

The RES Directive establishes a common framework for the promotion of energy from renewable sources. It sets a EU overall target for the total share of energy from renewable sources in gross final energy consumption in the Union in 2030 at $32 \%$. It also establishes rules on financial support for electricity from renewable sources and prosumption.

One of the main goals of the Winter Package is to make the electricity market customer-friendly. In the RES Directive, it is implemented by introducing rules facilitating the operation of renewable energy prosumers. The Directive ensures the right to become a prosumer of renewable energy, while maintaining the rights and obligations of the final consumer of energy. Prosumers can produce renewable energy, also for their own needs, store and sell surpluses of their renewable electricity produced through electricity suppliers or through peerto-peer arrangements. At the same time, they are not subject to discriminatory or disproportionate procedures, as well as to any fees that do not reflect real costs. They also have the right to participate in support schemes that cover energy from renewable energy entering the network.

The Winter Package also provides end users with the opportunity to participate in energy communities operating in the field of renewable energy while maintaining their rights and obligations as consumers, provided that their participation is not the main economic activity. Energy communities will have the right to produce, use for their own needs, store and sell renewable energy as well as access to all their respective energy markets. Importantly, the operator of a given distribution system should cooperate with such a community, and fees related to the use of the system should reflect the real level of costs, without inadequate fees
Such a shape of RES support regulation generates significant potential for the development of VPP systems, especially in the case of prosumers and energy communities. VPP is an ideal solution for energy communities that bring together renewable energy producers as well as energy consumers located in a small area. Unified basis for the functioning of such organizations, adapting the system to individual needs will allow to maximize the economic effect of these communities and allow better use of available resources to ensure the security of energy supply. [7]

\section{Summary}

Virtual Power Plants are an ideal tool that can meet the needs of modern energy sector in the management of a group of diversified energy units. The versatility of solutions and the ability to adjust the shape of VPPs to the needs makes that in the near future systems of this type will be used by an increasing number of entities. The regulatory environment will also be conducive to the development of VPP. The increasing amount of distributed renewable energy sources, and on the other hand, the ever-increasing balancing requirements will make the implementation of such systems necessary for conducting economically justified activities in this area. The new regulations also give opportunities for better use and giving more value to the flexibility of generating units and energy storage. All these factors in the near future will make VPP the most important tool for entities operating on the electricity market.

\section{References}

1. Bayar, T. (2013). Virtual Power Plants: A New Model for Renewables Integration. Renewable Energy World, Vol 16(5), 2013.

2. Ropuszynska-Surma, E., \& Weglarz, M. (2018). A Virtual Power Plant as a Cooperation Network. Marketing and Management of Innovations, 4, 136149.

3. Nikonowicz Ł., Milewski J., Virtual Power Plants general review: structure, application and optimization, Journal of Power Technologies 92 (3) (2012)

4. Rafał Magulski, Koncepcja funkcjonowania wirtualnej elektrowni integrującej rozproszone źródła energii jako dostawcy usług systemowych, Zeszyty Naukowe Wydziału Elektrotechniki $i$ Automatyki PG, Nr 53/2017 (2017)

5. Regulation (EU) 2019/943 of the European Parliament and of the Council of 5 June 2019 on the internal market for electricity.

6. Directive (EU) 2019/944 of the European Parliament and of the Council of 5 June 2019 on common rules for the internal market for electricity and amending Directive 2012/27/EU.

7. Directive (EU) 2018/2001 of the European Parliament and of the Council of 11 December 2018 on the promotion of the use of energy from renewable sources. 